\title{
Treat addictions with evidence, not ideology
}

\author{
Fiona Godlee editor in chief
}

The BMJ

The war on drugs is failing. This was the conclusion The BMJ reached at the end of last year, leading us to call for reform of drug policy (doi:10.1136/bmj.i6067). Evidence now supports decriminalisation of non-violent drug use, as do a growing number of health and human rights organisations. And the debate is moving cautiously towards support for legalised but heavily regulated drug markets.

Adding their voices to calls for drug legalisation are parents of young people who have died as a result of taking drugs. As Richard Hurley reports (doi:10.1136/bmj.j1876), an international campaign group called Anyone's Child aims to show the human cost of prohibition, which it says stigmatises people who use drugs, stops them getting information on what they are taking, and limits access to treatment for drug dependency. They envisage legalisation and regulation of the supply and use of drugs, with clear age limits and quality control. This would not mean a free for all, they say: "Our current laws already achieved that."

Our editorial last year prompted an early day motion in parliament and some supportive and well argued rapid responses (www.bmj.com/content/355/bmj.i6067/rapid-responses). Chris Ford and Sebastian Saville from International Doctors for Healthier Drug Policies called on doctors to be at the forefront of change, highlighting the poorer health outcomes from punitive rather than health related approaches. GP Richard Byng wrote of the effects of the wide range of available addictive substances that "dominate the lives of our patients": tobacco, alcohol, and prescribed and street drugs, making consultations "feel like being at the epicentre of contradictory policies and powerful marketing." He wants to see an overarching, coherent, and evidence based policy on all addictive or psychoactive substances, with more liberal laws for illegal drugs but tighter legislative control over tobacco and alcohol-“a compromise between the libertarian free market (still dominant with respect to alcohol) and paternalistic authoritarianism (still dominant with respect to heroin)."

He might have added problem gambling to the list. As Henrietta Bowden-Jones writes (doi:10.1136/bmj.j1593), this "hidden addiction" is clearly linked to increased crime and violence, mental illness, and family breakdown. She argues for problem gambling to be recognised as an illness, on an equal footing with other mental and physical illnesses. Psychological and drug treatments are supported by evidence, she says, and should be available on the NHS.

People need compassionate, non-judgmental treatment of their addiction, whatever the cause. And society needs to act to protect vulnerable people from harm, not through ideologically driven prohibition, which has never worked, but through evidence based, pragmatic policies that promote health and human rights: decriminalisation definitely; legalisation and tight regulation probably. 